\title{
A method for obtaining single cell responses in the optic tract of self-respiring fish
}

\author{
JEREMY M. SHEFNER and MICHAEL W. LEVINE \\ University of Illinois at Chicago Circle, Chicago, Mlinois 60680
}

\begin{abstract}
This paper describes a preparation for recording action potentials from the central nervous system of an intact self-respiring fish. The cervical spinal cord of the anesthetized fish was lesioned to minimize body movements, and the brain was exposed by cutting a hole in the dorsal skull. A clamp was attached to the rostral edge of this hole to eliminate motion of the skull. The fish in this preparation can control its own respiration and thus maintain an essentially normal respiratory state. This is a significant improvement over previous preparations, as respiratory state has been shown to be an important determinant of central nervous system function.
\end{abstract}

The properties of the visual system are commonly studied by investigations of prepared tissue from infrahuman species. Implicit in these studies is the assumption that these model systems are typical in the way they handle spatial, intensive, and chromatic information, and that the same underlying processes discovered in these preparations are operational in the behaving animal. Recently, however, experimenters have become increasingly aware that the respiratory state of the preparation, which in general is quite different from the natural state, may have a qualitative effect on the properties being studied.

One model system for which respiratory state has been shown to be an important determinant of visual function is the isolated retina of the common goldfish (Carassius auratus). In early experiments involving this preparation, retinae were respired by passing a mixture of $95 \% \mathrm{O}_{2}$ and $5 \% \mathrm{CO}_{2}$ over the distal side of the retina. Under these conditions, the ganglion cells isolated had a low or nonexistent maintained firing rate and possessed both a spectrally and spatially antagonistic receptive field organization (e.g., Daw, 1968; Spekreijse, Wagner, \& Wolbarsht, 1972; Wagner, MacNichol, \& Wolbarsht, 1960). However, Abramov and Levine (1972) found that when an isolated goldfish retina was respired by passing a stream of pure $\mathrm{O}_{2}$ over the distal side of the retina, ganglion cells exhibited properties quite different from those seen by previous workers. The maintained firing rate in the dark was found to be much higher, and cells were as much as $2 \log$ units more sensitive when respired with pure $\mathrm{O}_{2}$ than when the same cells were treated with a small percentage of $\mathrm{CO}_{2}$ mixed in the gas. In addition, although spatially antagonistic center and surround areas were usually observed in the ganglion cell receptive field, chromatic antagonism was almost never observed until $\mathrm{CO}_{2}$ was added to the gas mixture.

A closer approximation to the natural physiological state of the fish retina may be obtained by recording from the optic tract of the intact goldfish (e.g., Beauchamp \& Daw, 1972; Beauchamp \& Lovasik,
1973). In previous studies using intact goldfish, the animals were immobilized by the use of a curariform agent (e.g., gallamine triethiode, tubocurarine chloride) in order to allow stable placement of electrodes and prevent eye movements. Unfortunately, these agents also paralyze the respiratory apparatus of the fish, so the animals must be artificially respired by pumping a continuous flow of oxygenated water through the mouth and past the gills. While this method successfully sustains the life of the animal for the duration of the experiment, the appropriate flow rate has never been determined and the respiratory state of the retina is not controlled.

We have devised a method for immobilizing the goldfish without paralyzing his breathing apparatus, thus allowing the animal's normal homeostatic mechanisms to maintain the proper respiratory state. Fish are anesthetized with tricaine methanesulfonate (Finquel, Ayerst Labs), diluted to $100 \mathrm{mg} / 1$, by immersing them in the anesthetic solution for $10-20 \mathrm{~min}$. With this level of anesthesia, fish recover sufficiently to resume normal feeding and swimming behavior within $15 \mathrm{~min}$ after removal from the tricaine solution. As in the curarized fish preparations, the anesthetic is allowed to wear off following surgery.

The surgical procedure involves drilling a hole in the cranial roof about $1 \mathrm{~cm}^{2}$ in area. This hole extends caudally from the line connecting the centers of the eyeballs, so that both the olfactory lobes and the optic tecta are exposed. The fatty tissue overlying the brain is aspirated away, as are the olfactory lobes, exposing the optic chiasm and tracts (see Figure 1). The spine is severed just caudal to its exit from the cranial case by drilling directly down from the dorsal surface. This prevents any voluntary skeletal activity, but spares the cranial nerves responsible for mouth and gill motion.

The fish are held rigidly in the experimental chamber by tightly clamping the rostral edge of the cranial opening to a metal bar. This holds the skull absolutely still, while allowing free mouth and gill movements. 


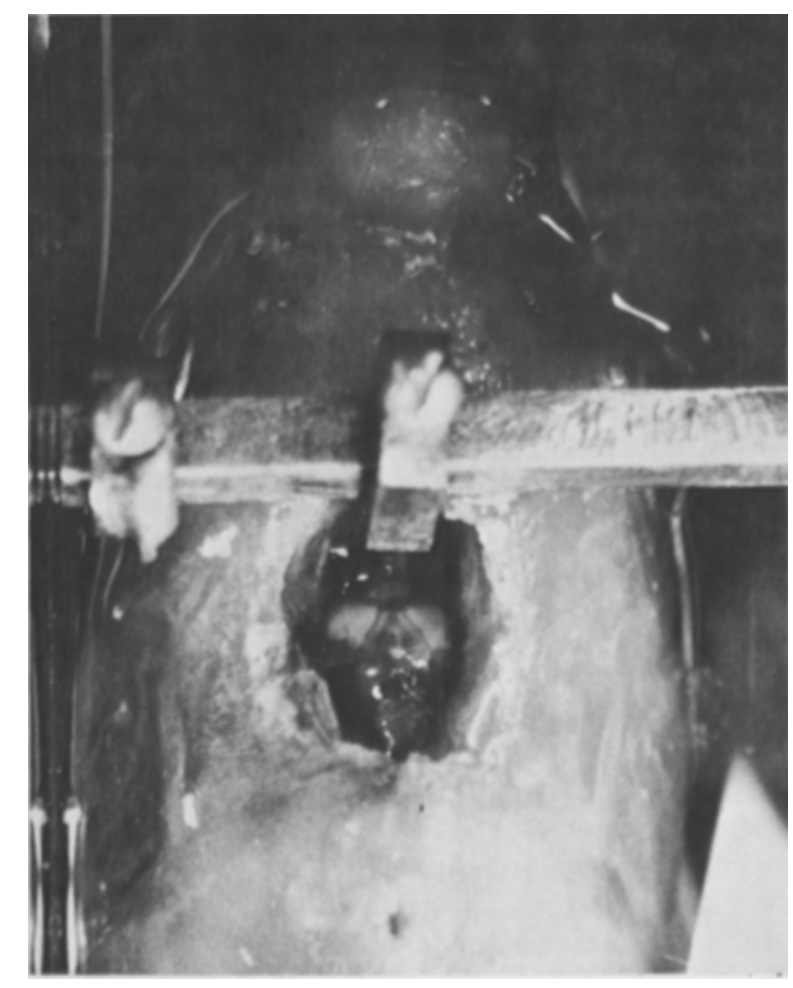

Figure 1. Top view of a fish in the apparatus. Optic tecta may be seen in the center of the opening in the skull. The small hole through which the spine was lesioned may be seen caudal to the large opening, near the bottom of the picture.

In the goldfish, this activity causes no significant brain movement. The left eye is immobilized by gluing the outside perimeter of the cornea to a metal ring with Eastman 910 cement (see Figure 2). The entire preparation is immersed in water so that the gills, mouth, and eyes are submerged, but water does not enter the opening on the dorsal aspect of the head. A microelectrode is lowered into the optic tract from above, while an indifferent electrode is implanted in the cut made for severing the spine. Stimuli are presented to the left eye through a Maxwellian-view optical system.

As a demonstration that the fish in this preparation can successfully control their respiratory states, we have allowed fish to survive clamped in the holder for periods of 72 to $96 \mathrm{~h}$. Of 21 fish so far studied with this preparation, all have survived for at least $24 \mathrm{~h}$ before being sacrificed. Perhaps a more sensitive indicator of the stability of this preparation is that, in one case, a single unit was continuously recorded in isolation for $24 \mathrm{~h}$, with no appreciable change in its response properties. The preparation is stable mechanically; cells typically are isolated for 2 to $4 \mathrm{~h}$, and we have never observed any significant shifts in the locations of receptive fields (as would be expected if the eye had moved) during the course of an experiment.
This preparation is useful for investigating the properties of the goldfish visual system in a condition closely approximating the natural state. Also, since respiratory movements are not paralyzed, they may be used to obtain behavioral correlates of the physiological responses being investigated. Classical conditioning of respiratory activity has been used to obtain psychophysical functions from restrained goldfish (Northmore \& Muntz, 1974; Otis, Cerf, \& Thomas, 1957; Shefner \& Levine, 1976). This preparation may allow the simultaneous application of the techniques of conditioning with those of single-unit recording.

\section{REFERENCES}

Abramov, I., \& Levine, M. W. The effects of carbon dioxide on the exposed goldfish retina. Vision Research, 1972, 12, 1881-1895.

Beauchamp, R. D., \& Daw, N. W. Rod and cone input to single goldfish optic nerve fibers. Vision Research, 1972, 12, 1201-1212.

BEAUCHAMP, R. D., \& Lovasik, J. V. Blue mechanism response of single goldfish optic fibers. Journal of Neurophysiology, 1973, 36, 925-939.

DAw, N. W. Colour-coded ganglion cells in the goldfish retina: Extension of their receptive fields by means of new stimuli. Journal of Physiology, 1968, 197, 567-592.

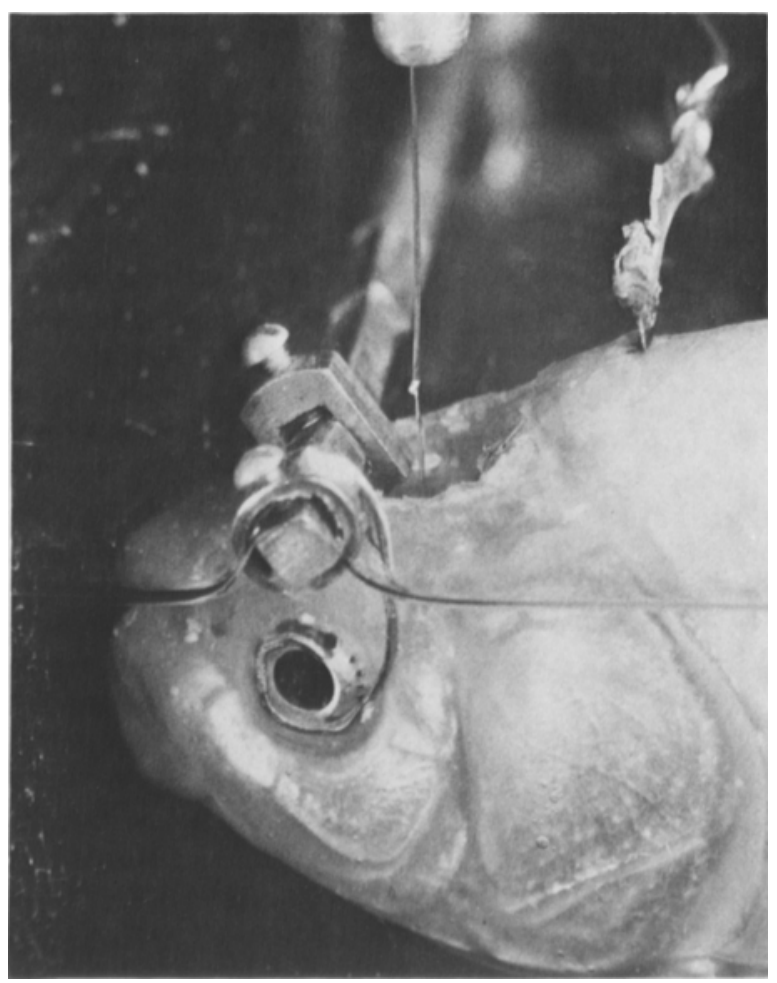

Figure 2. Side view of a fish in the apparatus. A microelectrode may be seen entering the cranial opening. 
Northmore, D. P. M., \& Muntz, W. R. A. Effects of stimulus size on spectral sensitivity in a fish (Scardinius erythrophthalmus), measured with a classical conditioning paradigm. Vision Research, 1974, 14, 503-514.

Otis, C. S., Cerf, J. A., \& Thomas, G. Conditioned inhibition of respiration and heartrate in the goldfish. Science, 1957, 126, 263-264.

SHefNer, J. M., \& Levine, M. W. A psychophysical demonstration of goldfish trichromacy. Vision Research, 1976, 16, 671-673.
Spekreijse, H., Wagner, H. G., \& Wolbarsht, M. L. Spectral and spatial coding of ganglion cell responses in goldfish retina. Journal of Neurophysiology, 1972, 35, 73-86.

Wagner, H. G., MacNichol, E. F., JR., \& Wolbarsht, M. L. The response properties of single ganglion cells in the goldfish retina. Journal of General Physiology, 1960, 43, Part II, 45-62.

(Received for publication July 16, 1976.) 